\title{
Apolipoprotein $B$ is regulated by gonadotropins and constitutes a predictive biomarker of IVF outcomes
}

\author{
Elodie Scalici ${ }^{1 *}$, Shaliha Bechoua ${ }^{2}$, Karine Astruc ${ }^{3}$, Laurence Duvillard ${ }^{4}$, Thomas Gautier ${ }^{5}$, Véronique Drouineaud ${ }^{6}$, \\ Clément Jimenez ${ }^{7}$ and Samir Hamamah ${ }^{8}$
}

\begin{abstract}
Background: Follicular fluid (FF) is an important micro-environment influencing oocyte growth, its development competence, and embryo viability. The FF content analysis allows to identify new relevant biomarkers, which could be predictive of in vitro fertilization (IVF) outcomes. Inside ovarian follicle, the amount of FF components from granulosa cells (GC) secretion, could be regulated by gonadotropins, which play a major role in follicle development.

Methods: This prospective study included 61 female undergoing IVF or Intra-cytoplasmic sperm injection (ICSI) procedure. Apolipoprotein B (APOB) concentrations in follicular fluid and APOB gene and protein expression in granulosa cells from reproductively aged women undergoing an in vitro fertilization program were measured. The statistical analyses were performed according to a quartile model based on the amount of APOB level found in FF.

Results: Amounts of APOB were detected in human FF samples (mean \pm SD: $244.6 \pm 185.9 \mathrm{ng} / \mathrm{ml}$ ). The odds of obtaining an oocyte in the follicle and a fertilized oocyte increased significantly when APOB level in FF was higher than $112 \mathrm{ng} / \mathrm{ml}$ [i.e., including in Quartile Q 2, Q3 and Q4] ( $p=0.001 ; p<0.001$, respectively). The probabilities of obtaining an embryo and a top quality embryo on day 2, were significantly higher if APOB levels were within the ranges of 112 and $330 \mathrm{ng} / \mathrm{ml}$ (i.e. in Q2 and Q3) or 112 and $230 \mathrm{ng} / \mathrm{ml}$ (i.e. in Q2), respectively ( $p<0.001 ; p=0.047$, respectively). In addition, our experiments in vitro indicated that $A P O B$ gene and protein expression, along with APOB content into culture were significantly under-expressed in GC upon stimulation with gonadotropins (follicular stimulating hormone: FSH and/or human chorionic gonadotropin: hCG).

Conclusion: We are reporting a positive and statistically significant associations between APOB and oocyte retrieval, oocyte fertilization, and embryo quality. Using an experimental study component, the authors report significant reduced $\mathrm{APOB}$ expression and content for luteinized granulosa cells cultured in the presence of gonadotropins.
\end{abstract}

Keywords: Apolipoprotein B, Human follicular fluid, IVF outcomes, Human granulosa cells, Gonadotropins

\section{Background}

Apolipoprotein B (APOB) is a major structural protein for atherogenic APOB-containing lipoproteins, including chylomicrons, Very-Low-Density Lipoprotein (VLDL), Intermediate-Density Lipoprotein (IDL) and LowDensity Lipoprotein (LDL). The APOB-containing lipoproteins contain large amounts of cholesterol and

\footnotetext{
* Correspondence: elodie.scalici@inserm.fr

'ART-PGD Department, INSERM U1203, Arnaud de Villeneuve Hospital, CHU Montpellier, Montpellier, France

Full list of author information is available at the end of the article
}

triglycerides (TG) and are involved in lipoprotein metabolism and plasma lipid transport [1-4].

These lipoproteins are secreted by enterocytes [5], hepatocytes [6], human placenta [7] and cardiomyocytes [8]. APOB synthesis and secretion are regulated by several hormonal factors in hepatocytes such as Growth Hormone [9], insulin [10], adrenocorticotrophic hormone [11] and thyroid hormones [12]. Interestingly, we demonstrated previously that human granulosa cells (GC) are also able to assemble and secrete APOB100containing lipoproteins [13]. Although GC functions are mostly influenced by gonadotropins, hormonal regulation 
of APOB expression in GC has never been investigated. Follicular fluid (FF), surrounding oocyte, provides an important microenvironment, influencing oocyte developmental competence and embryo development [14-16]. Therefore, recent works focused on FF analysis and identified in this fluid, potential biomarkers, which could be used to assess oocyte/embryo quality in order to improve the in vitro fertilization (IVF) success rates $[17,18]$. Only few studies reported the presence of VLDL, LDL and APOB in human FF $[13,19,20]$ and thus their relationships with IVF outcomes remain unknown.

This prospective translational study included two main objectives. First, we performed APOB quantification in individual FF samples $(n=201)$ from 61 patients undergoing IVF/Intra-cytoplasmic sperm injection (ICSI) program in order to investigate relationships between intra-follicular APOB levels and IVF/ICSI outcomes. Secondly, we explored hormonal regulation by gonadotropins of APOB expression in cultured human GC. To do so, in vitro studies were undertaken for which human $\mathrm{GC}$ isolated from FF were stimulated or not with gonadotropins (FSH and/or hCG). The apolipoprotein B gene and protein expressions in GC along with APOB content of the culture medium were investigated.

\section{Methods \\ Determination of APOB concentrations in blood-free FF samples, obtained from 61 female patients Patients' characteristics}

A total of 61 female patients between 24 and 42 years of age (mean \pm SD: $33.6 \pm 4.8$ years) and with a BMI between 16 and $35 \mathrm{~kg} / \mathrm{m}^{2}$ (mean \pm SD: $22.5 \pm 3.8 \mathrm{~kg} / \mathrm{m}^{2}$ ) were included in our prospective study. Among these patients, 16 were overweight or obese (BMI $>25 \mathrm{~kg} / \mathrm{m}^{2}$ ), whereas 3 were underweight $\left(\mathrm{BMI}<18.5 \mathrm{~kg} / \mathrm{m}^{2)}\right.$. These women underwent controlled ovarian stimulation (COS) followed by either IVF $(n=34)$ or ICSI $(n=27)$ procedure at the Assisted Reproduction Technology Department of the Dijon hospital (CHU de Dijon, France). Exclusion criteria included polycystic ovary syndrome or lipid metabolic disorders [21]. On average, the delay in conception was $3.6 \pm 1.8$ years. Forty three couples had primary infertility $(70.5 \%)$ and 18 couples secondary infertility $(29.5 \%)$. Fifty five couples were enrolled in IVF/ ICSI procedure for the first or second time. Female infertility, sperm abnormalities, mixed and unexplained infertility were diagnosed in $49.2 \%, 37.7 \%, 8.2 \%$, and $4.9 \%$ of the cases, respectively. Based on anti-müllerian hormone (AMH) and antral follicular count (AFC), all women had a normal ovarian reserve. The patients' clinical characteristics are summarized in Additional file 1: Table S1. Informed consents were obtained from all patients for the use of FF samples on the day of oocyte retrieval.

\section{IVF/ICSI procedure}

Sixty one patients underwent an agonist GnRH protocol including ovarian stimulation with recombinant FSH ( $r$ FSH) (Puregon, Schering Plough, Courbevoie, France or Gonalf, Merck Serono, Lyon, France). Ovarian stimulation response was monitored by both, serum estradiol concentration and transvaginal ultrasound assessment of follicular and endometrial growth.

Ovulation was induced with 6500 UI of recombinant hCG (Ovitrelle, Merck Serono, Lyon, France) when at least three follicles had reached $17 \mathrm{~mm}$ or more in diameter. Cumulus oocyte complexes (COC) were retrieved by transvaginal ultrasound-guided aspiration, $36 \mathrm{~h}$ after ovulation triggering, rinsed twice and isolated for conventional IVF or ICSI protocol. In ICSI procedure, after denudation, oocyte maturity was assessed and mature oocytes were micro-injected. Oocytes were individually maintained in $30 \mu \mathrm{l}$ microdrops of culture medium (Global Medium, LifeGlobal, USA) under oil at $37{ }^{\circ} \mathrm{C}$ in $6 \%$ $\mathrm{CO}_{2}$ and $5 \% \mathrm{O}_{2}$. Normal fertilization was checked between 16 and $18 \mathrm{~h}$ after insemination or microinjection by the presence of two pronuclei $(2 \mathrm{PN})$ and the two polar bodies. Early cleavage (EC) was evaluated 25 or $27 \mathrm{~h}$ after microinjection (ICSI) or insemination (IVF), respectively. Two days after oocyte retrieval, embryo quality was scored according to morphological criteria: (i) cleavage stage, (ii) number and size of blastomeres, and (iii) degree of fragmentation. An embryo was considered as a top quality embryo if there were 4 to 5 blastomeres on day 2 , less than $20 \%$ of fragments, and no multinucleation [22]. On day 2, the embryo(s) (standardof-care in the centre) was (were) transferred under transabdominal ultrasound guidance.

\section{$A P O B$ quantification by ELISA in individual FF samples}

For the 61 patients, at the day of oocyte retrieval, all the follicles visualized by ultrasound were aspirated individually without flushing. Only blood-free FF samples $(n=201)$ were collected and centrifuged at $3000 \mathrm{~g}$ for $15 \mathrm{~min}$. The supernatants were removed and stored at $80{ }^{\circ} \mathrm{C}$ for $\mathrm{APOB}$ quantification. APOB concentration in each FF sample was quantified using the Human APOB

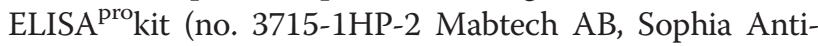
polis, France). Inter and intra-assay variation coefficients were $10.0 \%(\mathrm{CV})$ and $2.0 \%(\mathrm{CV})$, respectively.

\section{Quartile model}

Quartiles (Q) of APOB concentrations ( $\mathrm{ng} / \mathrm{ml}$ ) measured in the FF $(n=201)$ samples of the 61 patients were defined as followed: 
Q1: $\mathrm{APOB}<112 \mathrm{ng} / \mathrm{ml}$

Q2: $112<\mathrm{APOB}<230 \mathrm{ng} / \mathrm{ml}$

Q3: $230<\mathrm{APOB}<330 \mathrm{ng} / \mathrm{ml}$

Q4: $\mathrm{APOB}>330 \mathrm{ng} / \mathrm{ml}$

The patients' characteristics in each defined quartile are presented in Additional file 2: Table S2.

See statistical analysis section for further information.

\section{Are apolipoprotein B gene expression and protein level regulated in vitro by gonadotropins? \\ CG isolation}

GC were isolated from FF samples, collected the day of oocyte retrieval, as previously described [23]. Typically, FF from 6 or 7 women (undergoing oocyte retrieval the same day) with normal ovarian reserve were pooled and centrifuged at $300 \mathrm{~g}$ for $5 \mathrm{~min}$ and at $500 \mathrm{~g}$ for $5 \mathrm{~min}$, successively. This experiment was performed 10 times $(n=10)$. The cell layer was removed and re-suspended in DMEM/F12 medium supplemented with $10 \%$ foetal calf serum (FCS) and antibiotics (100 UI/ml of penicillin and $100 \mu \mathrm{g} / \mathrm{ml}$ streptomycin) (Invitrogen, France). Then, to separate GC from cellular debris, the cell suspension was centrifuged using a Puresperm gradient (Nidacon, Mölndal, Sweden). The GC layer was collected, washed and re-suspended in DMEM/F12 medium. In order to eliminate macrophages, GC suspension was allowed to settle for $20 \mathrm{~min}$ and the supernatant was centrifuged at $400 \mathrm{~g}$ for $30 \mathrm{~min}$. The final pellet was re-suspended in $1 \mathrm{ml}$ of DMEM/F12 medium and the cells suspension was distributed in each well at a density of $2 \times 10^{5}$ cells.

\section{Gonadotropin stimulation of GC primary culture}

GC were cultured in DMEM/F12 medium supplemented with $10 \%$ FCS and antibiotics for $72 \mathrm{~h}$ to regain a more native reaction pattern before hormonal stimulation [24]. After three days in culture, GC were either untreated (control) or treated for $48 \mathrm{~h}$ with $30 \mathrm{ng} / \mathrm{ml}$ of $\mathrm{r}$ FSH (Puregon ${ }^{\circ}$, Schering Plough, Courbevoie, France) or $30 \mathrm{ng} / \mathrm{ml}$ of hCG (Ovitrelle •, Merck Serono, Lyon, France), individually or in combination. One $\mu \mathrm{l}$ of Androstenedione (Sigma, Poole, UK) was added to the culture medium to provide specific substrate to $\mathrm{GC}$, for oestrogen synthesis. Therefore, $17 \beta$-estradiol quantification by immuno-chemiluminescence using a commercially kit (ADVIA $^{\circ}$ Centaur, Bayer Diagnostics, Tarrytown, NY, USA) allowed to check GC viability (Additional file 3: Figure S1). From day 3, FCS was replaced in culture medium by Nutridoma-CS (Roche Applied Science, Germany) in order to avoid lipoproteins contamination. After 5 days of culture, culture medium and GC samples were retrieved and stored at $-80{ }^{\circ} \mathrm{C}$. Each culture's experiment was performed in triplicate and 10 times.
Quantitative (real-time) PCR: APOB gene expression in GC Total RNA from GC was extracted using the Absolutely RNA Microprep kit (ref 400805, Agilent Technologies, Jolla, USA) according to manufacturer's recommendations and quantified by Nanodrop ND-1000. By adding $10 \mu \mathrm{l}$ of RT Buffer and $1 \mu \mathrm{l}$ of RT Enzyme Mix, $200 \mathrm{ng}$ of total RNA was reverse-transcribed into cDNA using the High Capacity RNA-to cDNA kit (Applied Biosystems, Foster City, USA). Quantitative PCR was performed from $5 \mu \mathrm{l}$ of cDNA, $10 \mu \mathrm{l}$ of Master Mix, $1 \mu \mathrm{l}$ of Master Assay and $4 \mu \mathrm{l}$ of $\mathrm{H}_{2} \mathrm{O}$, by using Taqman technology (Applied Biosystems, Foster City, USA). Each qPCR reaction contained specific primers of $A P O B$ gene (ref 4331182, ID assay: Hs00181142_m1; Applied Biosystems). The human housekeeping GAPDH gene (ref 4351372, ID assay: Hs04420697_g1; Applied Biosystems) was added in each qPCR template, as an endogenous control to normalize relative $A P O B$ gene expression in untreated (control) and treated GC samples. The GAPDH housekeeping gene was stably expressed in GC pools $(n=10)$ from different FF samples (Additional file 4: Figure $\mathrm{S} 2$ ). The $A P O B$ relative expression was calculated according to the equation $2^{-\Delta \Delta \mathrm{CT}}$ method.

\section{Western blot analysis: $A P O B$ protein expression in GC}

After the addition of LDS Sample buffer and reducing agent (Nupage, Invitrogen, France) to GC samples and incubation at $95{ }^{\circ} \mathrm{C}$ for $10 \mathrm{~min}$, each sample (containing $30 \mu \mathrm{g}$ of total protein per well) was applied onto 4-12\% polyacrylamide gradient gels (NuPage, Invitrogen, France) inserted in a X-Cell SureLock system (Invitrogen, France) and then blotted to nitrocellulose membranes (Protan, Schleicher and Schuell, Dassel, Germany). The membrane was saturated during one hour with Phosphate Buffered Saline (PBS), $0.1 \%$ Tween (PBS-T $0.1 \%$ ) and $5 \%$ low-fat dried milk. An incubation was performed overnight at $4{ }^{\circ} \mathrm{C}$, with a rabbit polyclonal human anti-ApoB100 antibody (H-300) (1:1000, sc- 25542, Biotechnology, Santa Cruz, USA), in PBS-T $0.1 \%$. Then, the membrane was incubated for one hour with an antirabbit HRP antibody (Biotechnology, Santa Cruz, USA) diluted in PBS-T $0.1 \%$ (1:5000). APOB was detected using Supersignal West Pico Trial kit (Thermoscientific, Rockford, USA) and ChemiDocTM XRS Embellish-Images LabTM 2.0 Software system (Bio-Rad).

\section{Slot Blot analysis: $A P O B$ content of the culture medium}

Culture medium samples $(300 \mu \mathrm{l})$ were applied onto nitrocellulose membrane (Protan, Schleicher and Schuell, Dassel, Germany) and the membrane was washed with Tris Buffer Saline (TBS) with $0.1 \%$ of Tween-20 (TBS-T $0.1 \%$ ), then saturated in TBS-T $0.1 \%$ containing $5 \%$ low-fat dried milk for one hour. The incubations were performed as described for western blots. 
Slot blots were detected using the Supersignal West Pico Trial kit (Thermoscientific, Rockford, USA) and analyzed using the ChemiDocTM XRS Embellish-Images LabTM 2.0 Software system (Bio-Rad).

\section{Statistical analyses}

The means \pm standard deviations (SD) and $95 \%$ confidence intervals $(\mathrm{CI})$ were reported for quantitative data and percentages for categorical ones. The comparisons of APOB concentrations according to IVF/ICSI outcomes were performed using Student's $t$-test. Then, simple linear regression models with robust variance estimates for cluster-correlated data were performed to analyze relationships between patients' characteristics and APOB concentration in FF. FF produced by the same women defined the cluster. FF APOB concentration effects on IVF/ICSI outcomes were estimated using univariate logistic regression. For each parameter, we compared the model including APOB concentration as a continuous variable with the model including APOB concentration quartiles as qualitative variables, to select and report the best one. The first quartile (Q1) was taken as the reference for the comparison with the other quartiles. Then, prognostic effect of patient's characteristics on IVF/ICSI outcomes was estimated using univariate logistic regression models. Each variable with $p<0.2$ was included in the multivariate logistic regression models and used to estimate the independent effect of APOB concentration in FF on IVF/ICSI outcomes. For all these logistic regression models, robust variance estimations for cluster-correlated data were used.

For in vitro studies, Mann-Whitney tests were used to compare $A P O B$ gene expression in treated and untreated GC.

Statistical analyses were performed using Stata 10.0 software. Results were considered significant when $p$-value $<0.05$.

\section{Ethical approval}

Ethical approval was obtained from the local Institutional Review Board, CHU of Dijon, France.

\section{Results}

APOB is present in human follicular fluid and provides a new biomarker to predict oocyte and embryo quality Relationships between $A P O B$ concentrations in FF and patient's characteristics (age, BMI, number of attempts)

Follicular fluid from young patients $(<36$ years, $n=41)$ contained significant higher APOB levels than FF obtained from older patients ( $>36$ years, $n=20)(\beta=-93.6$, $p=0.02$ ). Likewise, APOB levels in FF were significantly higher for patients with normal BMI compared to underweight $\left(\mathrm{BMI}<18.5 \mathrm{~kg} / \mathrm{m}^{2}\right)$ or obese patients $\left(\mathrm{BMI}>30 \mathrm{~kg} / \mathrm{m}^{2}\right)(\beta=-162.2, p=0.001$ and $\beta=-142.3$, $p=0.005$, respectively). In addition, FF related to women enrolled in a first or second attempt contained higher APOB levels than patients undergoing their third or fourth attempt $(\beta=-148.8, p=0.005)$ (Table 1$)$.

\section{$A P O B$ concentrations in individual FF samples according to IVF/ICSI outcomes}

Amounts of APOB were detected in 201 individual FF samples from pre-ovulatory follicles (mean \pm SD: $244.6 \pm 185.9 \mathrm{ng} / \mathrm{ml}$, median: $229.3 \mathrm{ng} / \mathrm{ml}$ ). In $90 \%$ of the samples analyzed $(n=182)$, APOB concentration was under $480 \mathrm{ng} / \mathrm{ml}$. Table 2 shows that APOB concentration was significantly higher in FF samples containing an oocyte $(n=143)$ than those related to empty zona pellucida $(n=58) \quad(271 \pm 181.8 \mathrm{ng} / \mathrm{ml}$ versus $179 \pm 181.3 \mathrm{ng} / \mathrm{ml}, p=0.001$, respectively). Likewise, FF samples related to normal fertilized oocytes $(n=107$, fertilization rate $=82.3 \%$, IC95 [75.7-89] $)$ contained significant increased APOB levels compared to those related to no fertilized oocytes $(n=23)$ $(279.8 \pm 168.0 \mathrm{ng} / \mathrm{ml}$ versus $162.6 \pm 192.5 \mathrm{ng} / \mathrm{ml}$, $p=0.004$, respectively). APOB levels were significantly also increased in FF samples associated with an embryo on day $2(n=92)$ compared to those associated with no embryo $(n=109) \quad(294.3 \pm 159.8 \mathrm{ng} / \mathrm{ml}$ versus $202.6 \pm 196.5 \mathrm{ng} / \mathrm{ml}, p<0.001$, respectively).

Moreover, when considering APOB divided into quartiles (Table 3), we found significant associations between APOB concentrations in FF and the probabilities to obtain an oocyte, a fertilized oocyte, an embryo and a top quality embryo on day $2(P=0.001$; $P<0.001, P<0.001, P=0,047$, respectively). Indeed if APOB levels were equal or higher to $112 \mathrm{ng} / \mathrm{ml}$ (i.e. including in Q2, Q3 or Q4), the odds of obtaining an oocyte, a normal fertilized oocyte, an embryo or a top quality embryo were significantly increased (Conditional Odds Ratio, COR: 3.9, 4.2 and 3.9; COR: 6.2, 10.1 and 6.4; COR: 15.2, 15.5 and 8; COR: 4.4, 4.2,

Table 1 Relationships between APOB concentrations in human FF and clinical prognostic markers of IVF success

\begin{tabular}{|c|c|c|c|}
\hline Variable & $\beta$ & Robust SE & $p$-value \\
\hline \multicolumn{4}{|l|}{ Age (years) } \\
\hline Age $>36$ versus $\leq 36$ & -93.6 & 37.7 & 0.02 \\
\hline BMI $\left(\mathrm{kg} / \mathrm{m}^{2}\right) 18.5 \leq \mathrm{BMI}<25$ (reference) & - & - & - \\
\hline $\mathrm{BMI}<18.5$ & -162.2 & 48.0 & 0.001 \\
\hline $25 \leq \mathrm{BMI}<30$ & -59.0 & 72.7 & NS \\
\hline $\mathrm{BMI} \geq 30$ & -142.3 & 48.6 & 0.005 \\
\hline \multicolumn{4}{|l|}{ Number of attempts } \\
\hline 3 and 4 versus 1 and 2 & -148.8 & 51.3 & 0.005 \\
\hline
\end{tabular}


Table 2 Comparisons of APOB concentrations in human FF according to IVF/ICSI outcomes

\begin{tabular}{|c|c|c|c|c|}
\hline \multirow[t]{2}{*}{ FF related to } & \multirow{2}{*}{$\begin{array}{l}\mathrm{n} / \text { number of FF } \\
\text { analyzed (\%) }\end{array}$} & \multicolumn{2}{|l|}{ APOB (ng/ml) } & \multirow[t]{2}{*}{$p$-value } \\
\hline & & Mean \pm SD & {$[95 \% \mathrm{Cl}]$} & \\
\hline Oocyte & $143 / 201(71.1)$ & $271.0 \pm 181.8$ & {$[240.9 ; 301.0]$} & $p=0.001$ \\
\hline Empty zona pellucida (no oocyte) & $58 / 201(28.9)$ & $179.0 \pm 181.3$ & {$[131.8 ; 227.2]$} & \\
\hline Normal fertilized oocytes & $107 / 201(53.2)$ & $279.8 \pm 168$ & {$[247.6 ; 312.0]$} & $p=0.004$ \\
\hline No fertilized oocytes & $23 / 201(11.4)$ & $162.6 \pm 192.5$ & {$[79.4 ; 245.8]$} & \\
\hline Embryo & $92 / 201(45.8)$ & $294.3 \pm 159.8$ & {$[261.2 ; 327.4]$} & $p<0.001$ \\
\hline No embryo & $109 / 201(54.2)$ & $202.6 \pm 196.5$ & {$[165.3 ; 239.9]$} & \\
\hline Early cleavage & 22 / 92 (23.9) & $352.1 \pm 192.6$ & {$[266.7 ; 437.5]$} & NS \\
\hline No early cleavage & $70 / 92(76.1)$ & $276.1 \pm 144.9$ & {$[241.6 ; 310.7]$} & \\
\hline Top quality embryo & 45 / $92(48.9)$ & $322.1 \pm 205.2$ & {$[260.4 ; 383.7]$} & NS \\
\hline No top quality embryo & 47 / $92(51.1)$ & $267.7 \pm 93.6$ & {$[240.2 ; 295.2]$} & \\
\hline
\end{tabular}

Values are reported by the number of variable ( $\mathrm{n}$ ) / number of FF analyzed (percentage of the total). The comparisons were performed using Student's $t$-test. $S D$ Standard Deviation, FF Follicular Fluid, NS No significant

4.4 in Q2, Q3 and Q4, respectively). Moreover, after adjustment for patients' characteristics, if APOB concentrations were above $112 \mathrm{ng} / \mathrm{ml}$ and within the ranges of Q2, Q3 or Q4, the probabilities of obtaining an oocyte and a fertilized oocyte remained significantly higher (AOR: 3.4, 3.3 and 3.4; AOR: 7.3, 11.2 and 6.3 in Q2, Q3 and Q4, respectively). However, after adjustment for patient's characteristics, the odds of obtaining an embryo remained significantly elevated only if $A P O B$ concentrations were included in Q2 and Q3 (between 112 and $330 \mathrm{ng} / \mathrm{ml}$ ) (AOR: 17.3, 15.5 in Q2 and Q3, respectively). Finally, the concentrations of APOB that could predict the odds of obtaining a top quality embryo on day $2(\mathrm{AOR}=4.8)$

Table 3 Probabilities of APOB concentration in human FF, divided into quartiles (Q), to predict IVF/ICSI outcomes

\begin{tabular}{|c|c|c|c|c|c|c|}
\hline APOB quartiles $(\mathrm{ng} / \mathrm{ml})$ & n / number of FF analyzed (\%) & $P$ & Crude OR $[95 \% \mathrm{Cl}]$ & $p$-value & Adjusted OR $\left[95 \% \mathrm{Cl}^{\mathrm{a}}\right.$ & $p$-value \\
\hline \multicolumn{7}{|c|}{ Probabilities of obtaining an oocyte } \\
\hline Q1 $(<112)$ & $24 / 50(48.0)$ & 0.001 & - (reference) & & - (reference) & \\
\hline Q2 $(\geq 112,<230)$ & $40 / 51(78.4)$ & & $3.9[1.65-9.4]$ & 0.002 & $3.4[1.04-11.2]$ & 0.044 \\
\hline Q3 $(\geq 230,<330)$ & 39/49 (79.6) & & $4.2[1.73-10,3]$ & 0.002 & $3.3[1.19-9.08]$ & 0.022 \\
\hline Q4 ( $\geq 330)$ & $40 / 51(78.4)$ & & $3.9[1.65-9.4]$ & 0.002 & $3.4[1.01-11.44]$ & 0.049 \\
\hline \multicolumn{7}{|c|}{ Probabilities of obtaining a fertilized oocyte } \\
\hline Q1(<112) & $12 / 50(24.0)$ & $<0.001$ & - (reference) & & - (reference) & \\
\hline Q2 $(\geq 112,<230)$ & $34 / 51(66.7)$ & & $6.2[1.79-21.76]$ & 0.004 & $7.3[1.59 ; 33.43]$ & 0.011 \\
\hline Q3 $(\geq 230,<330)$ & $33 / 49(67.3)$ & & $10.1[2.38-42.69]$ & 0.002 & $11.2[1.67 ; 75.63]$ & 0.013 \\
\hline Q4 ( $\geq 330)$ & 28/51 (55.0) & & $6.4[1.69-24.37]$ & 0.006 & $6.3[1.13 ; 34.86]$ & 0.035 \\
\hline \multicolumn{7}{|c|}{ Probabilities of obtaining an embryo on day 2} \\
\hline $\mathrm{Q} 1(<112)$ & $5 / 50(10.0)$ & $<0.001$ & - (reference) & & - (reference) & \\
\hline Q2 $(\geq 112,<230)$ & $32 / 51(62.8)$ & & $15.2[5.11-44.95]$ & $<0.001$ & $17.3[2.2 ; 137.1]$ & 0.007 \\
\hline Q3 ( $\geq 230,<330)$ & $31 / 49(63.3)$ & & $15.5[5.19-46.29]$ & $<0.001$ & $15.5[1.9 ; 130.3]$ & 0.011 \\
\hline Q4 ( $\geq 330)$ & $24 / 51(47.1)$ & & $8[2.72-23.51]$ & $<0.001$ & $8.3[0.8 ; 82.0]$ & 0.071 \\
\hline \multicolumn{7}{|c|}{ Probabilities of obtaining a top quality embryo on day 2} \\
\hline Q1(<112) & $4 / 50(8.0)$ & 0.047 & - (reference) & & - (reference) & \\
\hline Q2 $(\geq 112,<230)$ & $14 / 51(27.5)$ & & $4.4[1.32-14.38]$ & 0.016 & $4.8[1.04 ; 22.41]$ & 0.045 \\
\hline Q3 $(\geq 230,<330)$ & 13/49 (26.5) & & $4.2[1.24-13.86]$ & 0.021 & $4.1[0.75 ; 22.64]$ & NS \\
\hline Q4 ( $\geq 330)$ & $14 / 51(27.4)$ & & $4.4[1.32-14.38]$ & 0.016 & $3.9[0.64 ; 23.91]$ & NS \\
\hline
\end{tabular}

${ }^{a}$ Probabilities to obtain an oocyte and an embryo were adjusted for age and aetiology of infertility. Probabilities to obtain a fertilized oocyte and a top embryo were adjusted for age. Q1, quartile 1; Q2, quartile 2; Q3, quartile 3; Q4, quartile 4. Q1 was considered as the reference. OR Odds Ratio, Cl confidence intervals, FF Follicular Fluid, NS No significant 
were comprised between 112 and $230 \mathrm{ng} / \mathrm{ml}$ (i.e. including in Q2).

\section{Regulation in vitro of apolipoprotein B gene and protein} by gonadotropins

\section{$A P O B$ gene expression in GC stimulated by gonadotropins} $A P O B$ gene was significantly under-expressed in treated human GC compared to untreated cells (control). Indeed $A P O B$ gene expression decreased significantly after a treatment by FSH, hCG or FSH and hCG compared to control $(p<0.001 ; p<0.001 ; p<0.001$, respectively). Moreover, the down-regulation of $A P O B$ gene expression by FSH was significantly strengthened after introduction of hCG into the culture medium (FSH versus FSH and hCG, $p=0.019$ ) (Fig. 1).

\section{$A P O B$ protein expression in GC stimulated by gonadotropins}

As shown in Fig. 2a, an APOB band (APOB100) was detected in human GC samples. The intensity of this band was significantly decreased in GC stimulated by FSH, hCG or FSH and hCG compared to unstimulated GC (control) $(p=0.045 ; p=0.009 ; p=0.005$, respectively) (Fig. 2a and 2b). Moreover, APOB protein expression was significantly lower in GC, treated simultaneously with FSH and hCG compared to those treated only by FSH (FSH versus FSH and hCG, $p=0.01$ ) (Fig. 2b).

\section{$A P O B$ protein content in the culture medium}

Likewise, $\mathrm{APOB}$ was identified into culture medium (Fig. 3). Low APOB secreted into culture medium was found when GC were stimulated with gonadotropins, compared to control (no treatment). The inhibitory

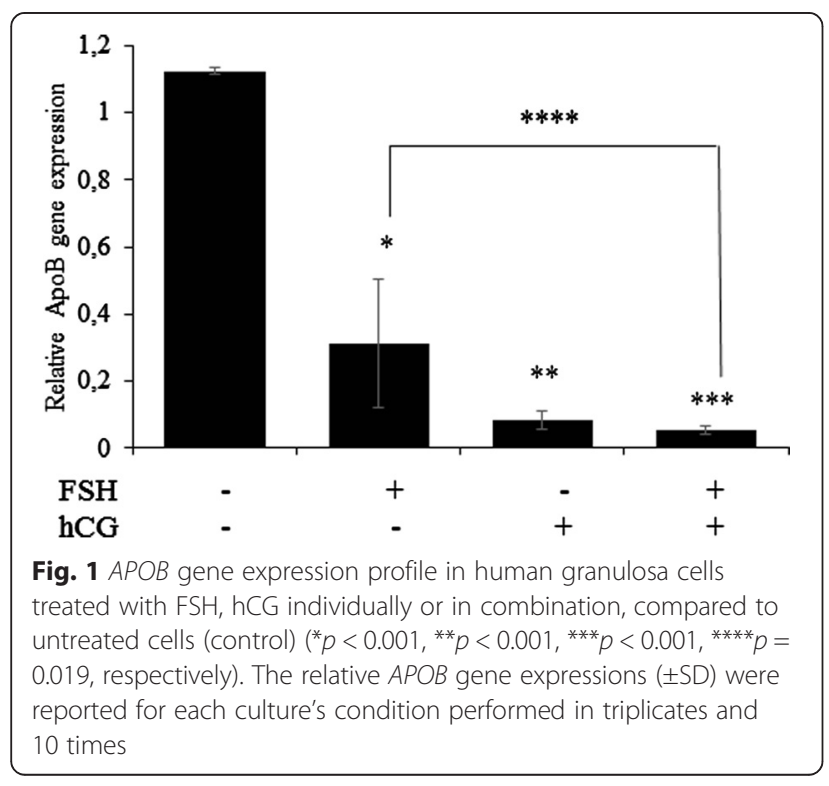

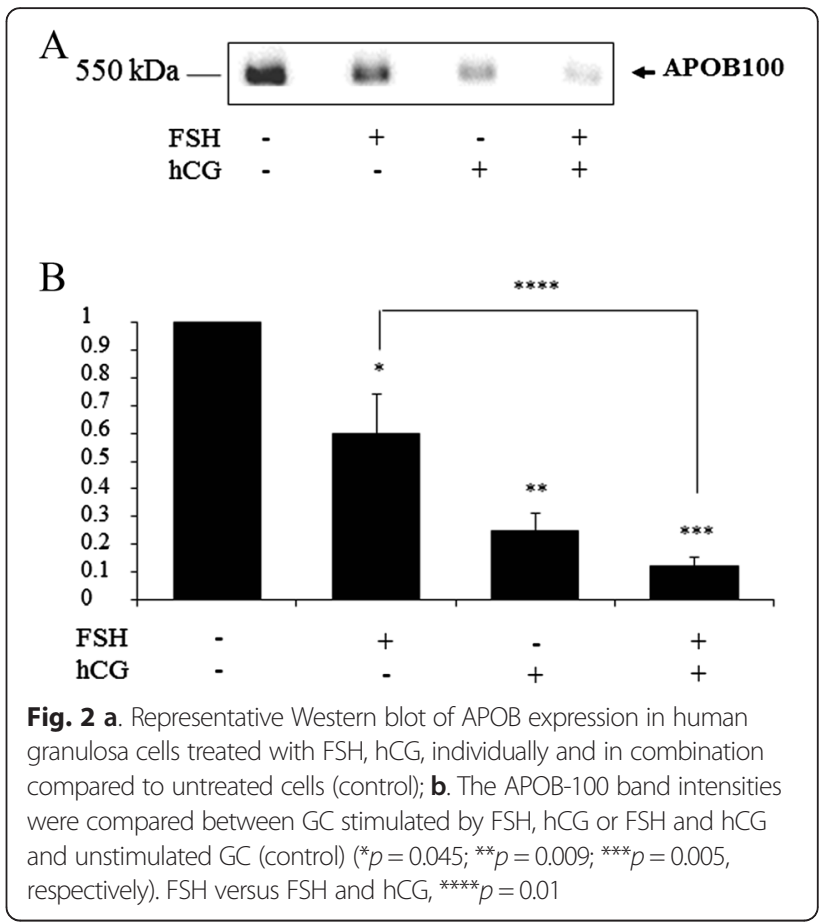

effect was synergized when the stimulation of GC was performed with both, FSH and hCG (Fig. 3).

\section{Discussion}

This study investigated the relationships between APOB concentrations in individual FF samples and IVF/ICSI outcomes, and the hormonal regulation of APOB expression in human cultured GC. Our results suggest that APOB could be used as a non-invasive biomarker to predict oocyte and embryo outcomes in patients undergoing IVF/ ICSI procedure. Moreover, APOB is down-regulated by gonadotropins (FSH and hCG) which could influence APOB content in ovarian follicle during COS. Several clinical parameters influence IVF/ICSI prognostic and outcomes. Interestingly, we showed that APOB concentration in FF was significantly related to some clinical characteristics. Indeed, APOB level appeared to be significantly higher in FF from women with good prognostic clinical markers such as young age, normal BMI and first or second IVF attempt. Aging is known to be associated with alterations of follicular environment and follicular cell functions, resulting in a decrease of some metabolic

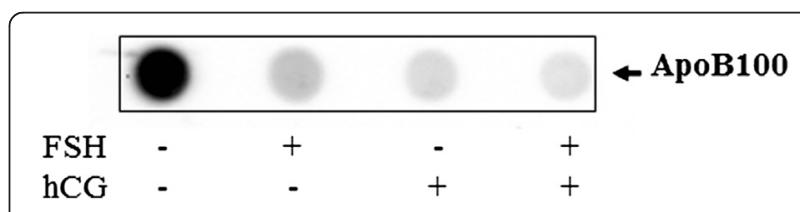

Fig. 3 Representative slot blots of APOB content into culture medium from granulosa cells treated with FSH, hCG, individually and in combination compared to untreated cells (control) 
components present in the FF [25]. Accordingly, intrafollicular APOB content could decrease with advanced age, leading to harmful effects on oocyte and embryo development. By contrast, one study reported low APOB levels in FF from young women ( $<35$ years) compared to older women ( $>40$ years) [20]. However, these results included a very low number of patients $(n=5$ for young women; $n=4$ for old women) compared to our study $(n=61)$. Likewise, increasing BMI was also associated with a decrease of APOB concentrations in FF which could be related to the follicular environment impairment in obese women at risk for poor reproductive performance [26]. One study investigated FF composition according to BMI classification. However in this study, APOB was not detected in the FF samples, most probably because of a lowsensitivity of the APOB assay method used [27]. In addition, it was reported that pregnancy rates decreased with repeated IVF attempts [28]. Therefore, women enrolled in a first or second attempt, have clinical parameters for prediction of success, related to a good health of recruited ovarian follicles which contain higher $\mathrm{APOB}$ concentrations. Moreover, the use of repeated ovarian stimulation treatment could induce changes in the composition of the follicular fluid [29]. This could explain the significant variations of intra-follicular APOB content according to the number of IVF attempts. Some FF components are involved in oocyte growth, oocyte developmental competence and embryo development. They provide non-invasive biomarkers of oocyte and/or embryo quality $[17,18]$. Likewise, we demonstrated that APOB concentration in FF was significantly associated with the probability to obtain an oocyte in the follicle, a normal fertilization, an embryo and a top quality embryo, respectively. Using a quartile model, we were able to demonstrate that the intra-follicular APOB level could be used to predict significantly and independently oocyte and embryo outcomes. It is conceivable that APOB in FF could play a role in the lipid transport as in plasma [1] and could supplies cholesterol and triglycerides (TG) to oocytes for supporting early embryo development. Indeed, TG act as an energy source during oocyte maturation and potentially during pre-implantation embryo development [30, 31]. Moreover, the pre-implantation embryo needs amounts of cholesterol for membrane formation during its cell cleavages [32-37]. Interestingly, LDL and VLDL receptors were already identified on chicken and mouse oocytes [38-40], but their presence have never been investigated in humans. In addition, a very high intra-follicular APOB level could affect embryo development and viability. Indeed, it is noteworthy to mention that an APOB concentration within the range of 112 and $230 \mathrm{ng} / \mathrm{ml}$ in FF appeared to be the optimal dose to obtain a top quality embryo. A large amount of APOB could reflect a lipidrich environment that could have a negative impact on oocyte quality and thus embryo development [41]. In addition, our data suggest that APOB could constitute a new promising biomarker, offering an additional tool to select the best embryo for replacement in order to improve IVF success rates.

Moreover, we reported in a previous work that GC have the ability to assemble and secrete ApoB100-containing lipoproteins [13]. Therefore, the second part of this present study consisted in understanding how the synthesis of APOB by GC could be regulated by gonadotropins and this knowing that these hormones are widely used in the field of IVF when performing ovarian stimulation. We showed that stimulation of cultured GC by gonadotropins (FSH or/and hCG) modified APOB expression and led to a significant decrease of its expression at the gene and protein level. In addition, GC treatment by gonadotropins reduced APOB protein content into the culture medium. Here, we are for the first time demonstrating that gonadotropins can regulate APOB level in an in vitro GC model. During IVF procedure, COS could contribute to modify FF composition and thus GC secretions [29]. One of the hypothesis would be that $\mathrm{APOB}$ is under-expressed in human GC upon a strong stimulation with gonadotropins. This, would create a poor availability of APOB in the follicular micro-environment leading to a disruption of lipid transfer from GC to oocyte.

One can reasonable assume that a young woman with good prognostic factors (normal BMI and first or second attempt) will need less FSH doses during ovarian stimulation than a woman with compromised prognostic factors (older woman, overweight). Indeed, this has been confirmed in our prospective study where we found that the "good prognosis" women needed lower dose of r-FSH than the "bad prognosis" women $(1892.4 \pm 756.6 \mathrm{IU}$ versus $2461 \pm 932.46 \mathrm{IU}, p=0.006$, respectively, data not shown). Therefore, the results obtained from the experiments in vitro (down regulation of APOB by FSH) could explain why APOB level was found significantly lower in patients with compromised prognostic factors compared to patients with good prognostic factors.

\section{Conclusions}

Our findings suggest that APOB could be easily quantified in order to identify and select among the embryos, the one that display all the morphological characteristics needed for a pregnancy to occur. Hence, APOB could be used as a prognostic biomarker when performing in vitro fertilization. Moreover, we are reporting for the first time a new regulation of APOB by gonadotropins in an in vitro human GC model. APOB was found to be downregulated by gonadotropin treatment in cultured human GC, suggesting a potential effect of COS on intrafollicular fluctuation of APOB concentrations during IVF/ ICSI procedure. 


\section{Additional files}

Additional file 1: Table S1. Patients' characteristics. All values are reported by the mean \pm SD (Standard Deviation) or the number of subjects (percentage of the total). BMI, Body Mass Index; IVF, In Vitro Fertilization; ICSI, Intracytoplasmic Sperm Injection. (DOCX 12 kb)

Additional file 2: Table S2. Description of patients' characteristics according to $\mathrm{APOB}$ concentrations divided into quartiles. Q1, quartile 1; Q2, quartile 2; Q3, quartile 3; Q4, quartile 4; SD, Standard Deviation; Cl, Confidence Intervals, BMI, Body Mass Index; IVF, In Vitro Fertilization; ICSI, Intracytoplasmic Sperm Injection. (DOCX 15 kb)

Additional file 3: Figure S1. $17 \beta$-estradiol quantification (ng/l) into culture medium by immuno-chemiluminescence. Androstenedione (And) was added to the culture medium to provide specific substrate to granulosa cells, for oestrogen synthesis. (TIF $69 \mathrm{~kb}$ )

Additional file 4: Figure S2. The constant GAPDH gene expression in GC pools $(n=10)$ under our experiment conditions. All Ct-values were reported for the different GC pools from FF samples. (JPG $137 \mathrm{~kb}$ )

\section{Abbreviations}

APOB: apoliprotein B; AFC: antral follicular count; $\mathrm{AMH}$ : anti-mullerian hormone; BMI: body mass index; Cl: confidence intervals; COC: cumulus oocyte complexes; EC: early cleavage; FCS: fetal calf serum; FF: follicular fluid; FSH: follicular stimulating hormone; GC: granulosa cells; GnRH: gonadotropin releasing hormone; hCG: human chorionic gonadotropin; IVF: in vitro fretilization; ICSI: intracytoplasmic sperm injection; PCR: polymerase chain reaction; Q: quartile; SD: standard deviation.

\section{Competing interests}

The authors declare no competing interests.

\section{Authors' contributions}

ES, CJ, VD conceived the experiments. ES, SB, CJ, VD analyzed and interpreted the data. ES, SB, SH drafted the manuscript and revised it critically for important intellectual content. KA performed the statistical analyses. TG, LD helped ES for some experimental design. ES performed the experiments. All authors critically revised the manuscript and approved the final version.

\section{Acknowledgments}

The authors gratefully acknowledge Mrs L. Loiodice and Mrs E. Niot from the biochemical laboratory, for their participation in APOB quantification, $\mathrm{Dr}$ Girod, Dr Huot and Pr Sagot from the ART department of the University Hospital of Dijon.

\section{Funding}

This study was supported by a grant from the Direction de la Recherche Clinique of $\mathrm{CHU}$ of Dijon and the Conseil Régional de Bourgogne and from ASGOD (Association des Gynécologues et Obstétriciens de Dijon).

\section{Author details}

'ART-PGD Department, INSERM U1203, Arnaud de Villeneuve Hospital, CHU Montpellier, Montpellier, France. ${ }^{2}$ University of Burgundy, UFR Sciences de Santé de Dijon, Dijon, France. ${ }^{3}$ Department of Epidemiology, Bocage Hospital, CHU Dijon, Dijon, France. ${ }^{4}$ Biochemistry Department, $\mathrm{CHU}$ Dijon, Dijon, France. ${ }^{5}$ INSERM UMR 866, lipids, Nutrition and Cancer, UFR of Medicine, Dijon, France. ${ }^{6} \mathrm{ART}$ Department, $\mathrm{CHU}$ de Dijon, Dijon, France. ${ }^{7}$ Service de Biologie de la Reproduction-CECOS, CHU de Bordeaux, Centre Aliénor d'Aquitaine, Bordeaux, France. ${ }^{8}$ ART-PGD Department, INSERM U1203, Arnaud de Villeneuve Hospital, CHU Montpellier, Montpellier, France.

Received: 21 December 2015 Accepted: 18 March 2016 Published online: 21 May 2016

\section{References}

1. Havel RJ. Lipoproteins and lipid transport. Adv Exp Med Biol. 1975;63:37-59.

2. Kane JP. Apolipoprotein B: structural and metabolic heterogeneity. Annu Rev Physiol. 1983:45:637-50.

3. Illingworth DR. Lipoprotein metabolism. Am J Kidney Dis. 1993;22:90-7.
4. Whitfield AJ, Barrett P, Hugh R, Van Bockxmeerfranck M, Burnett JR. Lipid disorders and mutations in the ApoB Gene: a review. Clin Chem. 2004;50:1725-32.

5. Xiao C, Lewis GF. Regulation of chylomicron production in humans. Biochim Biophys Acta. 2012;182:736-46.

6. Shelness GS, Sellers JA. Very-low-density lipoprotein assembly and secretion. Curr Opin Lipidol. 2001;12:151-7.

7. Madsen EM, Lindegaard LS, Andersen CB, Damm P, Nielsen LB. Human placenta secretes apolipoprotein B-100-containing lipoproteins. J Biol Chem. 2004;279:55271-6.

8. Veniant MM, Nielsen LB, Boren J, Young SG. Lipoproteins containing apolipoprotein B-100 are secreted by the heart. Trends Cardiovasc Med. 1999:9:103-7.

9. Lindén D, Sjöberg A, Asp L, Carlsson L, Oscarsson J. Direct effects of growth hormone on production and secretion of apolipoprotein $B$ from rat hepatocytes. Am J Physiol Endocrinol Metab. 2000;279:E1335-1346.

10. Patsch W, Franz S, Schonfeld G. Role of insulin in lipoprotein secretion by cultured rat hepatocytes. J Clin Invest. 1983;71:1161-74.

11. Xu N, Ekstrom U, Nilsson-Ehle P. ACTH decreases the expression and secretion of apolipoprotein B in HepG2 cell cultures. J Biol Chem. 2001; 276:38680-4.

12. Theriault A, Ogbonna G, Adeli K. Thyroid hormone modulates apolipoprotein B gene expression in HepG2 cells. Biochem Biophys Res Commun. 1992;186:617-23.

13. Gautier T, Becker S, Drouineaud V, Ménétrier F, Sagot P, Nofer JR, von Otte S, Lagrost L, Masson D, Tietge UJ. Human luteinised granulosa cells secrete ApoB100-containing lipoproteins. J Lipid Res. 2010;51:2245-52.

14. Revelli A, Delle Piane L, Casano S, Molinari E, Massobrio M, Rinaudo P. Follicular fluid content and oocyte quality: from single biochemical markers to metabolomics. Reprod Biol Endocrinol. 2009;7:40.

15. Wallace M, Cottell E, Gibney MJ, McAuliffe FM, Wingfield M, Brennan L. An investigation into the relationship between the metabolic profile of follicular fluid, oocyte developmental potential, and implantation outcome. Fertil Steril. 2012;97:1078-84.

16. O'Gorman A, Wallace M, Cottell E, Gibney MJ, McAuliffe FM, Wingfield M, Brennan L. Metabolic profiling of human follicular fluid identifies potential biomarkers of oocyte developmental competence. Reproduction. 2013;146:389-95.

17. Lédée N, Gridelet V, Ravet S, Jouan C, Gaspard O, Wenders F, Thonon F, Hincourt N, Dubois M, Foidart JM. Impact of follicular G-CSF quantification on subsequent embryo transfer decisions: a proof of concept study. Hum Reprod. 2013;28:406-13.

18. Scalici E, Traver S, Molinari N, Mullet T, Monforte M, Vintejoux E, Hamamah S. Cell-free DNA in human follicular fluid as a biomarker of embryo quality. Hum Reprod. 2014:29:2661-9.

19. Volpe A, Coukos G, Uccelli E, Droghini F, Adamo R, Artini PG. Follicular fluid lipoproteins in preovulatory period and their relationship with follicular maturation and progesterone production by human granulosa-luteal cells in vivo and in vitro. J Endocrinol Invest. 1991;14:737-42.

20. Von Wald T, Monisova Y, Hacker MR, Yoo SW, Penzias AS, Reindollar RR, Usheva A. Age-related variations in follicular apolipoproteins may influence oocyte maturation and fertility potential. Fertil Steril. 2010;93:2354-61.

21. Rotterdam ESHRE/ASRM-Sponsored PCOS consensus workshop group. Revised 2003 consensus on diagnostic criteria and long-term health risks related to polycystic ovary syndrome (PCOS). Hum Reprod. 2004:19:41-7.

22. Van Royen E, Mangelschots K, De Neubourg D, Valkenburg M, Van de Meerssche M, Ryckaert G, Eestermans W, Gerris J. Characterisation of a top quality embryo, a step towards single-embryo transfer. Hum Reprod. 1999; 14:2345-9.

23. VandeVoort CA, Overstreet JW, Lasley BL, Stewart DR. Effects of progesterone receptor blockers on human granulosa-luteal cell culture secretion of progesterone, estradiol, and relaxin. Biol Reprod. 2000;62:200-5.

24. Lindeberg M, Carlström K, Ritvos O, Hovatta O. Gonadotrophin stimulation of non-luteinized granulosa cells increases steroid production and the expression of enzymes involved in estrogen and progesterone synthesis. Hum Reprod. 2007:22:401-6.

25. Pacella L, Zander-Fox DL, Armstrong DT, Lane M. Women with reduced ovarian reserve or advanced maternal age have an altered follicular environment. Fertil Steril. 2012;98:986-94.

26. Robker RL, Akison LK, Bennett BD, Thrupp PN, Chura LR, Russell DL, Lane M, Norman RJ. Obese women exhibit differences in ovarian metabolites, 
hormones, and gene expression compared with moderate-weight women. J Clin Endocrinol Metab. 2009;94:1533-40.

27. Valckx SD, De Pauw I, De Neubourg D, Inion I, Berth M, Fransen E, Bols PE, Leroy JL. BMI-related metabolic composition of the follicular fluid of women undergoing assisted reproductive treatment and the consequences for oocyte and embryo quality. Hum Reprod. 2012;27:3531-359.

28. Meldrum DR, Silverberg KM, Bustillo M, Stokes L. Success rate with repeated cycles of in vitro fertilization-embryo transfer. Fertil Steril. 1989;69:1005-9.

29. de los Santos MJ, García-Láez V, Beltrán-Torregrosa D, Horcajadas JA, Martínez-Conejero JA, Esteban FJ, Pellicer A, Labarta E. Hormonal and molecular characterization of follicular fluid, cumulus cells and oocytes from pre-ovulatory follicles in stimulated and unstimulated cycles. Hum Reprod. 2012;27:1596-605.

30. Betteridge KJ, Fléchon JE. The anatomy and physiology of preattachement bovine embryos. Theriogenology. 1988;29:155-87.

31. Ferguson EM, Leese HJ. A potential role for triglyceride as an energy source during bovine oocyte maturation and early embryo development. Mol Reprod Dev. 2006;73:1195-201.

32. Pratt HP. Lipids and transitions in embryos. In: Johnson MH, editor. Development in mammals. Amsterdam: Elsevier; 1978. p. 83-130.

33. Pratt HP, Keith J, Chakraborty J. Membrane sterols and the development of the preimplantation mouse embryo. J Embryol Exp Morphol. 1980;60:303-19.

34. Pratt HP. Phospholipid synthesis in the pre-implantation mouse embryo. J Reprod Fertil. 1980;58:170-8.

35. Pratt HPM. Preimplantation mouse embryos synthetize membrane sterols. Dev Biol. 1982:89:101-10.

36. Pratt HPM. Membrane organization in the preimplantation mouse embryo. J Embryol Exp Morphol. 1985;90:101-21.

37. Pratt HPM, George MA. Organisation and assembly of the surface membrane during early cleavage of the mouse embryo. Roux's Arch Dev Biol. 1989;9:170-8

38. Sato N, Kawamura K, Fukuda J, Honda Y, Sato T, Tanikawa H, Kodama H, Tanaka T. Expression of LDL receptor and uptake of LDL in mouse preimplantation embryos. Mol Cell Endocrinol. 2003;202:191-4.

39. Yamaguchi YL, Tanaka SS, Kasa M, Yasuda K, Tam PP, Matsui Y. Expression of low density lipoprotein receptor-related protein 4 (Lrp4) gene in the mouse germ cells. Gene Expr Patterns. 2006;6:607-12.

40. Schneider WJ. Receptor-mediated mechanisms in ovarian follicle and oocyte development. Gen Comp Endocrinol. 2009:163:18-23.

41. Yang X, Wu LL, Chura LR, Liang X, Lane M, Norman RJ, Robker RL. Exposure to lipid-rich follicular fluid is associated with endoplasmic reticulum stress and impaired oocyte maturation in cumulus-oocyte complexes. Fertil Steril. 2012;97:1438-43.

\section{Submit your next manuscript to BioMed Central and we will help you at every step:}

- We accept pre-submission inquiries

- Our selector tool helps you to find the most relevant journal

- We provide round the clock customer support

- Convenient online submission

- Thorough peer review

- Inclusion in PubMed and all major indexing services

- Maximum visibility for your research

Submit your manuscript at www.biomedcentral.com/submit

) Biomed Central 